Edith Cowan University

Research Online

ECU Publications 2013

2013

Information Behavior and Japanese Students: How Can an

Understanding of the Research Process Lead to Better

Information Literacy?

Yusuke Ishimura

Edith Cowan University

Follow this and additional works at: https://ro.ecu.edu.au/ecuworks2013

Part of the Information Literacy Commons

10.1080/15228959.2013.758977

This is an Author's Accepted Manuscript of an article published as: Ishimura, Y. (2013). Information behavior and Japanese students: how can an understanding of the research process lead to better information literacy? Public Services Quarterly, 9(1), 20-33. Published online on 20th February, 2013 [copyright Taylor \& Francis], available online here

This Journal Article is posted at Research Online.

https://ro.ecu.edu.au/ecuworks2013/39 


\title{
Information Behavior and Japanese Students: How Can an Understanding of the Research Process Lead to Better Information Literacy?
}

\begin{abstract}
Academic librarians are striving to better serve international students as this emerging population grows on university campuses. Past studies of international students generally focus on linguistic and cultural differences in relation to information literacy skills development. However, it is necessary to go beyond these factors to better serve the population. By using a framework based in information behavior research, the present study investigates the factors that mediate students' behavior and information literacy skills. Practical recommendations based on the findings of an indepth qualitative study of students' research process are provided.
\end{abstract}

\section{Background}

North American university campuses have increasingly become multicultural as students worldwide seek better education opportunities. Many universities also actively recruit international students to add campus diversity and contribute economically. The expected benefits from the perspective of both students and institutions are reflected in current demographic changes. Over the last decade, the international student population has increased $30 \%$ in the United States and 60\% in Canada (Institute of International Education, 2010; Statistics Canada, 2011). Although academic institutions welcome them, it is also true that the students' experience after enrolment is sometimes neglected (Lee \& Rice, 2007). In addition to emphasizing self-responsibility, there are various venues through which universities can serve international students by improving their learning environment.

Considering the challenges inherent in navigating today's information intense environment, information literacy skills are fundamental for students to learn how to interact with information and become lifelong learners. The American Library Association (ALA, 1989) defined information literacy as skills in recognizing information needs, and finding, evaluating, and using information effectively for problem solving or decision making. The skills are essential for many situations for achieving academic success. 
However, as a report from the Society of College, National and University Libraries in the United Kingdom (2008) points out, academic librarians struggle to answer the question of how they can support international students with diverse needs, experiences, and expectations. How should librarians tackle this challenge of diversity in order to facilitate information literacy skills?

\section{Objectives}

This paper draws from the author's recent study that investigates Canadian and Japanese undergraduate students' research process and information literacy skills during academic tasks. This article focuses on sub-objectives of the study, investigating: 1) what factors are involved in Japanese students' information behavior during the research tasks and 2) what information literacy skills are present in their behavior. The results of this study provide insight on how librarians can better serve diverse populations in support of information literacy skills development.

\section{Literature Review}

The relationship between international students and academic libraries has been studied for more than 20 years, and three major areas of difficulty related to information skills have been identified: 1) English proficiency, 2) knowledge of academic library systems, and 3) understanding of academic expectations in North America. For example, in terms of communication skills, lower English proficiency limits students' understanding of assignment requirements, leads to miscommunication with librarians, and limits understanding of library instruction (Baron \& Strout-Dapaz, 2001; Jackson, 2004; Morrissey \& Given, 2006). Students often encounter library systems that are different from their home countries-if they have ever used libraries at all. For example, they may not be familiar with reference tools, librarians' roles 
in providing assistance, open stacks, online catalogues and databases, and classification systems (Allen, 1993; Ball \& Mahony, 1987; Goudy \& Moushey, 1984; Koehler \& Swanson, 1988; Liu, 1993; Macdonald \& Sarkodie-Mensah, 1988). In addition, in many cultures, students are expected to memorize and recall information from experts rather than critically synthesizing information, and therefore face difficulties in independent information gathering tasks (Badke, 2002; Ball \& Mahony, 1987; Macdonald \& Sarkodie-Mensah, 1988).

Interventions to overcome these difficulties have been discussed in previous literature, which also revolves around these three categories. For example, in-service training programs for librarians may be beneficial for improving communication skills (Ball \& Mahony, 1987; Greenfield, Johnston, \& Williams, 1986; Hensley \& Love, 2011). Libraries can provide bilingual library instruction (Bosch \& Molteni, 2011) or multilingual library guides and tours (Hensley \& Love, 2011; Liu, 1993).

Collaborative instruction among librarians, English as a second language (ESL) teachers, and faculty members is one of the most commonly observed approaches to help international students overcome linguistic barriers effectively (e.g., Bagnole \& Miller, 2003; Conteh-Morgan, 2001; Hensley \& Love, 2011; Ormondroyd, 1989).

However, Varga-Atkins and Ashcroft (2004) did not find major differences in the information skills levels of international and domestic students in the United Kingdom. Their findings suggest that looking only at the barriers may distract librarians from more important elements, and it is necessary to go beyond the categorization of "problems" to uncover the more elusive causal elements. 


\section{Conceptual Framework}

This study was framed by Wilson's (1999) definition of information behavior, which is composed of information needs, seeking, and use. In order to complete assignment tasks, students are expected to identify their focus, seek out information, and utilize it in a final product (e.g., a presentation or term paper). During their tasks, each part of the process is affected by elements that are both internal and external to information seekers. Thus, Wilson's (1997) conceptual model is the baseline framework used in this paper to identify what kind of intervening factors affect students' research process. His model provides useful key ideas to reveal mediating factors that influence students' research behavior, such as various preventive or supportive variables that are involved in information behavior (e.g., psychological, demographic, role-related or inter-personal, environments). The model also includes the concept of selfefficacy during seeking information. A single factor or a combination of several factors may have impact on the effectiveness and efficiency of students' behavior during their academic tasks.

Although this framework is useful to understand the nature of the process, information behavior models do not usually address the outcomes of the behavior according to recommended guidelines. Many academic librarians use the Association of College and Research Libraries' (ACRL, 2000) Information Literacy Competency Standards for Higher Education to structure instruction efforts. Using the standards sheds light on students' abilities to conduct individual research tasks, but assessment according to static standards does not answer how certain behavior determines the quality of students' output. In addition to information literacy standards, then, librarians can refer to information behavior models to make sense of students' complicated work processes. As shown in Table 1, information literacy standards and information behavior models each have three major components (i.e., information needs, seeking, and use). The 
approaches complement each other to reveal a more complete picture of students' information literacy competencies.

\section{Methods}

\section{Participants}

The term "international students," can be problematic. For example, American students in Canadian universities and vice versa are usually categorized as "international" for administrative purposes. In this paper, the term "international" refers to students who have a different cultural and linguistic background from North America. The student groups are very diverse and it is very challenging to generalize them. Thus, as a first step to understand the population, Japanese students in Canadian universities were selected as a sub-population for this study. They are one of the major international student groups on North American campuses, and the author's communication abilities enabled the capture of these students' authentic voices and experience. Since the objective is to investigate students who are new to the North American education system, Japanese participants were defined as having been born and primarily educated in Japan.

Participants were enrolled in 300 or 400 level undergraduate courses that included research paper assignments in two universities in Montreal, Quebec. Recruitment used purposeful sampling methods to reach potential participants. This was carried out through Japanese student societies and social media groups, and additional participants were identified using snowball sampling (Patton, 2002). In total, eight Japanese participated in this study (See Table 2). The study obtained research ethics approval at the researcher's university.

\section{Data collection and analysis}

This study used three data collection methods: 1) research portfolios, 2) in-depth semistructured interviews, and 3) flowcharts. Research project portfolios were used to capture 
students' information behavior in-depth. Students recorded evidence of information behavior during their assignment tasks such as the search process, actions taken, reflection on their actions, drafts, and final products (Salvia, Ysseldyke, \& Bolt, 2007). In order to facilitate continuous data collection, they were regularly contacted by e-mail to track their progress. In addition to the research portfolios, two in-depth semi-structured interviews were conducted with each participant so that the researcher could understand students' perspectives of their research experience from their points of view. Finally, following Kuhlthau's (2004) approach, participants drew flowcharts as a method of data collection, which gave the researcher a broad view of students' research steps, strategies, and decision making points. The data collected from the three methods were consolidated and analyzed using constant comparative methods (Glaser \& Strauss, 1967). For students' information literacy skills, ACRL's information literacy standards were used for assessment. All students' behavior was checked for the outcomes outlined in the standards. The assessment was made on a very broad level, with each outcome marked "missing," "partially satisfied," or "strongly satisfied" for each participant.

\section{Results}

Several factors were identified that mediate students' information behavior during research tasks. Four primary factors are discussed in this paper, namely 1) assignment guidelines, 2) interaction with domestic students, 3) past learning and personal interests, and 4) time allocation. In addition, these factors' associations with information literacy skills are presented. This study examined information literacy outcomes in depth, but the purpose of this paper is to address larger implications of behaviors in relation to information literacy skills. 


\section{Assignment guidelines}

Some librarians may agree with Ball and Mahony’s (1987) argument that international students often do not know "where or how to begin a research project" (p. 162). However, if professors provide detailed guidelines for assignments, it is easier for students - especially those who are unfamiliar with academic expectations in North America— to find a path to complete their tasks. For example, one participant in the study described why it was helpful to have a specific research topic assigned:

The topics assigned in class were relatively detailed. If the topics were broad, it would be very difficult to find a focus, for example, cancer. But this is very detailed . . . In the past, I could select any topic for one assignment . . . but I was not sure where to find information because there were so many papers on the topic. [J1]

When the students seek information, the assignment guidelines help them understand what types of sources to look for. One participant described her professor's guidelines:

In Japan, faculty did not specify what kind of sources I had to use. So I just searched the internet and found a book from the library and submitted a book review. But when I came here, professors told me I had to use academic sources, popular sources, newspaper articles, and this journal. I think this is a big difference [between Japan and Canada]. [J5]

Another participant had a different experience due to ambiguous guidelines. She was confused about the requirement to use "outside" sources:

I was not told how many [books or journals] need to be used. But, when someone asked the question, the prof told us that the course pack was required, but you don't have to do "comprehensive" research ... His directions were really vague. I really don't know [what to do]. [J7]

In addition to simply gathering information, students, of course, need to use facts and analysis in the context of their assignments. Students in the study mentioned that if professors provided guidelines on how papers should be structured, they relied on them heavily to know what to include. One participant said:

... The format was described in the outline [assignment guideline]. I looked at this outline. And I was told in class that first, I should provide background information about the company $\ldots$ the $2^{\text {nd }}$ and $3^{\text {rd }}$ pages were supposed to be the connection between advertisements and class content, and the $4^{\text {th }}$ page was about competitors ..., and the $5^{\text {th }}$ page is the conclusion. So I wrote my paper as directed . . [J4] 
These instances illustrate that the degree to which professors provide guidance has a huge impact on whether international students understand what to do in terms of the assignment requirements.

From an information literacy perspective, clear guidelines helped four students to strongly satisfy outcomes under ACRL Standard 1.2, which refers to skills in recognizing types of information and how these are used in a given discipline. Three students showed partial achievement of the outcomes in the standard. Assignment guidelines also affected a few students' outcomes related to defining an overall plan as described in Standard 1.3.

\section{Interaction with domestic students}

Several participants in the study described how peers influenced their behavior. In many cases, Japanese students recognized domestic peers as "role models," although these students were not necessarily effective in their own practices. For example, one Japanese participant recounted how he did not understand academic expectations in Canada. He thought that he was supposed to analyze raw data, but this is not often required in undergraduate level work. His Canadian friend helped him to better understand what to do for his paper:

I thought analyzing data and finding sources was tricky. In particular, it was almost the last minute when I realized that I had to find outside sources [e.g., journal articles]. I thought "Seriously?" because my friend told me that "I used 30 sources." . . I thought something is wrong because I didn't use any single source (laugh). [J2]

Other participants' comments revealed that observation of peers' behavior affected their approaches to seeking information. One student discovered that her classmates used the library catalog to locate relevant sources. She tried to imitate their behavior but she did not have full confidence as to why this was appropriate. She commented:

It's trial and error [to look for information]. Like, first, I look for information in the library catalog, then go to a website and type keywords and read the information found. . . Well, everyone is using the catalog, so I thought the catalog [is the right place to search] (laugh) ... I am curious [how other students do research], but I don't ask much because I have too many things to do and cannot think about anything more. I think many students type something in the catalog for their research. [J3] 
In another instance, a student thought she should change her behavior after observing domestic students. Interestingly, even though she had used academic libraries and asked librarians for help in Japan, she thought that the web was the most appropriate place to find information when doing academic work in Canada.

I didn't use the internet for research in Japan. But I think, in particular, people in the faculty of management use the internet extensively. So I was looking at it and started using it . . In Japan, I went to the library and asked librarians questions ... [J4]

Some students in the study also referred to the need to use appropriate citation styles in their work. One Japanese student's friend told her to use a web-based citation generator to format her reference list. With the friend's help, she at least understood that she needed to use a certain citation style. However, this did not necessarily mean that she truly understood the concept. She expressed feelings of difficulty:

The [university] library website has citation guides and there is a citation machine online. So I always use it. My friend told me about it. But I don't know how to use it yet. For example, the trickiest thing is that I still don't know the difference between journals and magazines. Also, what does "volume" mean? I skipped everything I don't know ... During group work, I was asked to format citations using APA. I asked "what is that?" A member of the group opened this program and told me to just put everything in here. [J4]

Overall, these examples demonstrate that peers' behavior can positively and negatively affect international students' behavior during the research process.

The idea of Canadian peers as role models for Japanese students has rich implications for improving international students' information literacy skills. The "help" factor enabled four Japanese students to identify types and formats of information, which is specified in ACRL Standard 1.2. In addition, four students selected appropriate investigative methods and information retrieval systems as described in Standard 2.1 (the other four satisfied partially the outcome). Although peers helped four Japanese students realize that using a particular citation style was important, they did not show an understanding of citation mechanisms. Thus, they 
partially satisfied the outcome that refers to formatting citations in Standard 5.3 (the other four students partially satisfied this).

\section{Past learning and personal interests}

Caveats about generalizations aside, international students often face challenges in completing work that comes more easily to domestic students. However, participants in the study employed various coping strategies. For example, a few students deliberately selected topics that were already familiar to them. With pre-existing background knowledge, students were more confident in their abilities to complete the assignment. This helped them to feel optimism rather than panic. The approach of selecting a familiar topic is also effective to supplement students' disadvantages in English language proficiency. One student felt that her skills were limited and tried to think of strategies for matching domestic students' speed in the assignment process.

I am planning to write a paper using my previous knowledge and books from the library to supplement what I am missing. I cannot read or write (it takes time to look over grammar) as fast as native speakers, so I thought I could select a topic that is at least easier. [J3]

Another student wanted to apply what he learned to show the originality of his ideas and distinguish himself from his classmates. He described:

I wanted to use econometrics which I studied in a [Japanese] university. So I selected a topic for which I can obtain data and that matches with what the professor is claiming, which supports the professor's opinion. In addition, since I am Japanese, if I can write a report which only Japanese can do, I thought I can show originality. [J2]

He added that this approach was effective to stay motivated. He was also able to find data in Japanese more easily than in English.

These examples show that topic selection —in relation to students' inherent characteristics as international students — was associated with reducing anxiety, increasing motivation, and supplementing language skills for more effective task completion. In this study, an explicit connection between these factors and specific outcomes in the standards was not 
found. However, the factors indicate a connection to students' overall performance, which will be an important element for librarians to design educational interventions.

\section{Time allocation}

While some professors use formative assessment methods to observe students' progress, others employ only summative assessment. In many cases, success or failure in the required tasks is evaluated according to the final products. Even if students spend a long time selecting topics and gathering information, poor output results in failure. Thus, time management skills are a good indicator of students' information behavior and of the areas in which they go off track. For example, one student described how she divided her time equally for selecting a topic, gathering information, and writing. Another student described how much time she spent seeking information:

Even if I enter keywords [in the catalog], the information is huge, it's too much. And I found books, but it's too much. How can I say, I cannot find information thoroughly. And then, I read slowly. There is a low probability that I can find what I want to find within the time frame or I cannot find it at all . . . I think if I have a bit more time, I could write a more detailed paper. [J3]

This example shows that certain steps become unbalanced without time management skills. Students they have difficulties completing tasks on time or compromise certain steps. Another student explained that she did not have enough time to complete certain tasks-especially in gathering information. Time pressures forced her to move to the next step of writing the paper, despite not being able to find what she was looking for.

Time management ability is an overarching element of the entire research process and is tied to outcomes in Standard 1.3. With this ability, a few students were able to create an overall plan for the assignment and allocate time appropriately. For example, demonstrating sophisticated skills in gathering information does not guarantee successful task completion (i.e., using information effectively). It seems that this is an advanced skill, as only two students 
demonstrated mastery of the outcomes of Standard 1.3, due in part to challenges related to time management in information behavior.

\section{Discussion}

The literature on international students frequently refers to challenges that students face in North American universities: language proficiency, knowledge of academic library services, and academic expectations. These challenges were found to be relevant in the current study as well. However, focusing only on these elements diverts librarians' attention from other important factors that affect international students' behavior and skills. By examining the research process and going beyond information literacy standards, alternative views of their challenges emerge.

\section{Assignment guidelines}

This study found that clear assignment guidelines enabled Japanese students to understand what do for their tasks. In addition, the guidelines helped them to satisfy information literacy outcomes related to identifying sources and recognizing the overall picture of research process. Librarians and professors alike need to provide scaffolding during students' assignment process. Although it is usually professors who create assignments, there are a few strategies that librarians can adopt to help international students. Librarians in outreach or "liaison" roles can actively collaborate with professors to design more explicit assignment guidelines that would benefit all students, and international students in particular. This does not necessarily entail stepby-step instructions, but it is important to explicitly state expectations and not take for granted requirements such as using outside sources and employing appropriate citation structures. Librarians are well-placed to raise professors' awareness of students' gaps in understanding, since they observe students working independently in authentic situations. In addition, in their interactions with students, librarians should be sensitive to the possibility that students may not 
understand the expectations for their assignments and encourage them to seek additional clarification from professors and teaching assistants.

\section{Interaction with domestic students}

Findings from the study presented here found that international students learned from domestic students' knowledge and behavior, which influenced the Japanese students' information behavior and skills. However, although they could demonstrate some of the baseline skills, they expressed a lack of understanding as to why these behaviors were appropriate. Therefore, there is an interesting insight on controlling this factor for academic librarians such as pairing international students with domestic in mentoring relationships. In previous studies that matched host students with international peers, international students benefitted on personal and academic levels, namely emotional support, language abilities, intercultural skills, and selfconfidence (Cheng, Myles, \& Curtis, 2004; Mendelsohn, 2002; Shigaki \& Smith, 1997). In a library setting, it is not realistic to pair students in one-shot workshops or reference interviews, but this approach could be part of orientation activities or large-scale information literacy programs. Moreover, librarians can target domestic students who serve as peer mentors with "train the trainer" programs and awareness-raising campaigns. Domestic students do not necessarily have a strong understanding of academic expectations and library skills. If influential domestic students' information literacy skills and awareness of library assistance improve, international students will also benefit.

\section{Past learning and personal interests}

It is commonly accepted that meaningful, effective learning builds on previous knowledge (Davis, 2009). In the context of research assignments, then, it is appropriate for students to build on what they already know and are interested in. In this study, use of previous 
learning helped them overcome challenges that arise from limited language proficiency and increase motivation to complete assignments (i.e., strong self-efficacy). However, in some cases, assignments are structured so that students cannot select topics related to their home countries. Sometimes, professors do not accept the use of non-English materials, since the instructor would not be able to assess whether they were used appropriately. Simply prohibiting the use of examples and sources from students' home countries, though, would not be effective. Rather, it is important that faculty and librarians collaborate to teach students how they can find information on their countries in an appropriate manner. If librarians have the opportunity to offer information literacy instruction specifically for international students, they could include exercises and tips on how to seek out sources from particular countries in addition to introducing materials and tools available uniquely in the host country.

\section{Time allocation}

Often, librarians focus only on information-gathering tasks in their interactions with students. However, as this study shows, students experience the research process as an integrated whole. Information seeking is just one part of the process. All students find time allocation to be a challenge, but the difficulties are exacerbated for international students, who typically require more time for orienting themselves to assignment expectations and for reading and writing in English. Therefore, helping students to understand the importance of time allocation during the research process would be useful. By discussing the big picture-with an emphasis on the fact that information-gathering can be endless_-students can be better informed and develop strategies for allocating time. To this end, for example, librarians can help students create flowcharts and diaries to document their process and recommend ideal elements to include (e.g., Nutefall, 2004). This can help them diagnose where difficulties occurred and identify places to 
improve. Kuhlthau's (2004) Information Search Process can be introduced to students as examples of typical processes that students might experience. Time management skills help students understand the "big picture" of the entire process and thereby make good use of available time. When librarians look at how students spent time in certain parts of the process, they can better diagnose where students' behavior could be improved in relation to information literacy.

\section{Conclusion}

In sum, the information behavior factors outlined in this study can affect a single aspect or the entire process of assignment completion. By identifying the specific factors that affect students' behavior - in particular, those that go beyond cultural and linguistic differenceslibrarians can anticipate challenges and provide needed assistance to international students. Professors and librarians can collaborate and supplement each other's efforts in providing explicit assignment guidelines and facilitating students' choices in pursuing research topics that build on their past learning and information gathering experiences. Librarians can also leverage domestic students' influence on their international peers by targeting information literacy efforts toward students in leadership roles. Finally, librarians can acknowledge the holistic nature of the research process in their information literacy instruction, recognizing that international students have unique time-management challenges that result from their linguistic and cultural differences. 


\section{References}

Allen, M. B. (1993). International students in academic libraries: A user survey. College \& Research Libraries, 54(4), 323-333.

American Library Association. (1989). Presidential committee on information literacy: Final report. Retrieved from http://www.ala.org/ala/acrl/acrlpubs/whitepapers/presidential.cfm

Association of College and Research Libraries. (2000). Information literacy competency standards for higher education. Chicago, IL: Author.

Badke, W. (2002). International students: Information literacy or academic literacy? Academic Exchange Quarterly, 6(4), 60-65.

Bagnole, J. W., \& Miller, J. W. (2003). An interactive information literacy course for international students: A practical blueprint for ESL learners. TESL-EJ, 6(4), 1-25.

Ball, M. A., \& Mahony, M. (1987). Foreign students, libraries, and culture. College \& Research Libraries, 48(2), 160-166.

Baron, S., \& Strout-Dapaz, A. (2001). Communicating with and empowering international students with a library skills set. Reference Services Review, 29(4), 314-326.

Bosch, E. K., \& Molteni, V. E. (2011). Connecting to international students in their languages: Innovative bilingual library instruction in academic libraries. In P. A. Jackson \& P. Sullivan (Eds.), International students and academic libraries: Initiative for success (pp. 135-150). Chicago, IL: Association of College and Research Libraries.

Cheng, L., Myles, J., \& Curtis, A. (2004). Targeting language support for non-native English speaking graduate students at a Canadian university. TESL Canada Journal, 21(2), 5071.

Conteh-Morgan, M. E. (2001). Empowering ESL students: A new model for information literacy instruction. Research Strategies, 18(1), 29-38.

Davis, B. (2009). Tools for teaching (2nd ed.). San Francisco, CA: Jossey-Bass.

Glaser, B. G., \& Strauss, A. L. (1967). The discovery of grounded theory: Strategies for qualitative research. Chicago, IL: Aldine.

Goudy, F. W., \& Moushey, E. (1984). Library instruction and foreign students: A survey of opinions and practices among selected libraries. Reference Librarian, 10 (Spring/Summer), 215-226. 
Greenfield, L., Johnston, S., \& Williams, K. (1986). Educating the world: Training library staff to communicate effectively with international students. Journal of Academic

Librarianship, 12(4), 227-231.

Hensley, M. K., \& Love, E. (2011). A multifaceted model of outreach and instruction for international students. In P. A. Jackson \& P. Sullivan (Eds.), International students and academic libraries: Initiative for success (pp. 115-134). Chicago, IL: Association of College and Research Libraries.

Institute of International Education. (2010). Open Doors 2010. New York, NY: Author.

Jackson, P. A. (2004). Incoming international students and the library: A survey. Reference Services Review, 33(2), 197-209.

Koehler, B., \& Swanson, K. (1988). ESL students and bibliographic instruction: Learning yet another language. Research Strategies, 6(4), 148-160.

Kuhlthau, C. C. (2004). Seeking meaning: A process approach to library and information services (2nd ed.). Norwood, NJ: Ablex.

Lee, J., \& Rice, C. (2007). Welcome to America? International student perceptions of discrimination. Higher Education, 53(3), 381-409. doi:10.1007/s10734-005-4508-3

Liu, Z. (1993). Difficulties and characteristics of students from developing countries in using American libraries. College \& Research Libraries, 54(1), 25-31.

Macdonald, G., \& Sarkodie-Mensah, E. (1988). ESL students and American libraries. College \& Research Libraries, 49(5), 425-431.

Mendelsohn, D. (2002). The lecture buddy project: An experiment in EAP listening comprehension. TESL Canada Journal, 20(1), 64-73.

Morrissey, R., \& Given, L. M. (2006). International students and the academic library: A case study. Canadian Journal of Information \& Library Sciences, 30(3/4), 221-239.

Nutefall, J. E. (2004). Paper trail: One method of information literacy assessment. Research Strategies, 20(1/2), 89-98.

Ormondroyd, J. (1989). The international student and course-integrated instruction: The librarian's perspective. Research Strategies, 7(4), 148-158.

Patton, M. Q. (2002). Qualitative research \& evaluation methods. Thousand Oaks, CA: Sage. 
Salvia, J., Ysseldyke, J. E., \& Bolt, S. (2007). Assessment in special and inclusive education. Boston, MA: Houghton Mifflin.

Shigaki, I. S., \& Smith, S. A. (1997). A cultural sharing model: American buddies for international students. International Education, 27(Fall), 5-21.

Society of College, National and University Libraries. (2008). Library services for international students. Retrieved from http://www.sconul.ac.uk/groups/access/papers/international_students.pdf

Statistics Canada. (2011). A changing portrait of international students in Canadian universities. Retrieved from http://www.statcan.gc.ca/pub/81-004-x/2010006/article/11405-eng.htm

Varga-Atkins, T., \& Ashcroft, L. (2004). Information skills of undergraduate business students: A comparison of UK and international students. Library Management, 25(1/2), 39-55. doi:10.1108/01435120410510247

Wilson, T. D. (1997). Information behaviour: An interdisciplinary perspective. Information Processing \& Management, 33(4), 551-572.

Wilson, T. D. (1999). Models in information behaviour research. Journal of Documentation, 55(3), 249-270. doi:10.1108/EUM0000000007145 